\title{
Abatement of odour emissions by UV/ozone oxidation process
}

\author{
Oliva G.*, Naddeo V., Zarra T. and Belgiorno V. \\ Sanitary and Environmental Engineering Division (SEED), Department of Civil Engineering, University of Salerno \\ Received: 20/06/2018, Accepted: 22/10/2018, Available online: 25/10/2018 \\ *to whom all correspondence should be addressed: e-mail: goliva@unisa.it \\ https://doi.org/10.30955/gnj.002798
}

\section{Abstract}

The growing expectations of the population and the increasingly stringent regulations about air pollution have resulted in the need to minimize and conveniently treat the waste gas from different emission sources. The emissions from a large variety of plants, including waste and wastewater treatment plants, result mainly from the degradation of organic matter. These emissions are composed of a complex of substances emitted at low concentrations from diffusive sources. These characteristics make complex their treatment in economically efficient conditions. The design and management of environmental protection and industrial plants, therefore, require the implementation of focused processes for the control of the target compounds. The present study shows the applicability of an UV-Ozone lab-scale system for odours and VOCs removal. An artificial gaseous stream contaminated by toluene, at different incoming concentrations, was treated evaluating the abatement efficiencies in terms of odours and total VOCs as a function of power and contact time. The residue ozone concentrations was determined in order to optimize the set-up conditions. The results were discussed with the aim of evaluating the feasibility of the investigated solution for the advanced treatment of the waste gas from environmental facilities. Removal efficiencies up tp 91\% were reached for the investigated conditions. Lower inlet concentrations resulted in high residue ozone outgoing the processes and, thus, it resulted over dimensioned for inlet load lower than 1,22 mg per minute.

Keywords: VOCs, odours, AOPs, UV, ozone.

\section{Introduction}

The emission of Volatile Organic Compounds (VOCs) is of great concern in the management of a variety of facilities including wastewater treatment, composting, industrial and CAFO (Concentrated Animal Feeding Operations) plants, and landfill, due to their toxicity, odour pollution and contribution to photochemical oxidants (Wang et al., 2013; Navia and Muñoz, 2015). Beside the effects on environment and human health, these emissions may cause odour annoyance among the population living surrounding the plants. The odour management is always more becoming a major issue for industrial operators (Belgiorno et al., 2012). The urbanized areas have been expanding increasingly closer to industrial sites and, consequently, it results no longer effective to rely on buffer distances to avoid odour pollution (Naddeoa et al., 2016a; Zarra et al., 2008; Hołub, 2014).

Odours can substantially result in an environmental discomfort which may cause psychophysiological disorders, such as nausea, headaches, insomnia, loss of appetite or respiratory problems, and to a general worsening of life quality (Zarra et al., 2009; Lucernoni et al., 2016; Naddeoa et al., 2016a).

These aspects have led to the need of defining suitable tools to face the increasing number of administrative and legal complaints, merged in stricter regulations regarding emission and exposure levels (Zarra et al., 2012; Naddeo et al., 2013; Estrada et al., 2015; Naddeoa et al., 2016b).

The necessity to address compliance to regulations and good public image has forced the polluting plants to adopt effective off-gas abatement technologies (Mudliar et al., 2010; Lebrero et al., 2011). The most widespread technologies for odour abatement are biological and chemical-physical processes (Bindra et al., 2015; Iranpour et al., 2005). Biotechnologies represents an economic and environmental-friendly waste gas treatment solution. These technologies result also suitable for high concentrations of compounds containing sulphur, chlorine, and/or nitrogen, showing an high efficiency for biodegradable compounds. However, biomass builds up have to be disposed as waste and percolate water needs treatment; furthermore, poorly soluble components result difficult to abate and toxic compounds inhibit the process. Chemical-physical processes, instead, represent proven and tested technologies, resulting effective for large air volumes. These processes, however, promote the transfer of the contaminants from gaseous phase to liquid or solid phases, with the need of further treatments (Alfonsin et al., 2015; Bindra et al., 2015; Estrada et al., 2015).

To overcome the limitations of the conventional processes, the scientific literature has focused the attention on the Advanced Oxidation Processes (AOPs) as alternative technologies applicable to a wide variety of polluting compounds and at different range of concentrations (Paz, 
2010; Idi et al., 2015; Yao and Feilberg, 2015; Swetha et al., 2017).

Among the AOPs, the $\mathrm{UV} / \mathrm{O}_{3}$ process addresses the decomposition of gaseous VOCs providing direct photolysis by UV, direct oxidation by ozone molecules, and indirect oxidation by hydroxyl radicals. 185 and $254 \mathrm{~nm}$ dominant UV wavelengths are usually investigated to study the photochemical reactions of organic compounds in liquid and gas phases. The presence of water vapor allow the absorption at UV range of 100-200 $\mathrm{nm}$. The dissociation of water vapor into hydrogen and hydroxyl radicals follows the equation (1) (Chou et al., 2005).

$$
\mathrm{H}_{2} \mathrm{O}+\mathrm{hv} \rightarrow \cdot \mathrm{OH}+\cdot \mathrm{H}
$$

Moreover, at wavelengths of $300 \mathrm{~nm}$ it is possible to detect also the conversion of ozone molecule into an oxygen molecule and an $\mathrm{O}\left({ }^{1} \mathrm{D}\right)$ atom and reacts with water vapor to form two hydroxyl radicals. These mechanisms are described by equation (2) and (3) (Chou et al., 2005).

$$
\mathrm{O}_{3}+\mathrm{hv} \rightarrow \mathrm{O}_{2}+\mathrm{O}\left({ }^{1} \mathrm{D}\right)
$$

$$
\mathrm{O}\left({ }^{1} \mathrm{D}\right)+\mathrm{H}_{2} \mathrm{O}+\mathrm{hv} \rightarrow 2 \cdot \mathrm{OH}
$$

The hydroxyl radicals generated as showed in the equation 2 and 3 may, consequently, react with organic compounds, addressing their decoposition (Chou et al., 2005).

The present work illustrates the applicability of an UV-Ozone lab-scale system for odours abatement and VOCs removal from an artificial gaseous stream contaminated by toluene, selected as target VOC.

The preliminary results of the study were discussed in terms of toluene and odours concentrations reduction, aiming at evaluating the performances of the investigated configurations as a function of the applied voltage and the incoming toluene concentrations.

The main results highlight the suitability of the advanced ozonation UV-inducted process for the treatment of off-gas from a great variety of odours emitting plants.

\section{Materials and methods}

\subsection{Experimental set-up}

The experiments were carried out in a lab-scale plant consisting in a steel photo-reactor composed of a central body $(48.6 \mathrm{~cm}$ length $\times 33.7 \mathrm{~cm}$ height $\times 17.8 \mathrm{~cm}$ width) in which are located four UV lamps and two pyramidal-truncated hoods (25 cm height). The UV lamps are able to generate ozone. The scheme of the experimental system is shown in Figure 1 . For the generation of the synthetic odorous waste stream, a metered stream of oil-free compressed air was passed through a Woulff-bottle pure toluene (Sigma Aldrich; CAS: 108-88-3) containing. This concentrated vapor was diluted to the expected concentration with oil-free water- saturated compressed air (Wang et al., 2013). The waste gas stream was then fed to the reactor. In Table 1 are reported the main operating parameters of the realized experimental set-up. In the Table 2 are reported the main parameter of the lamps used for the experimental activity.

\subsection{Analytical methodology}

Gas phase toluene concentration was measured using a Photoionization Detector (PID, Tiger, Ion Science) at point $P 1$ and P2. Toluene removal efficiency $(\eta)$ was calculated as follows:

$$
\eta=\frac{C_{\text {toluene, in }}-C_{\text {toluene, out }}}{C_{\text {toluene, in }}} \cdot 100 \%
$$

The ozone generated by the UV lamps and the output residue ozone were measured by the Standard Method 2350E 106 (Ozone Demand/Requirement-Semi-Batch Method). In Table 3 is reported the dependence of ozone generation rate on the applied voltage, obtained for an airflow rate equal to $13 \mathrm{lpm}$. The ozone generated resulted not linear dependent from the number of lamps on, expressed as applied voltage. This effect was probably related to the position of the lamps on and to the geometry of the reactor. The lamps which were not directly invested from the airflow contributed least to the ozone production. In the investigated conditions of airflow and humidity, the maximum value of ozone produced was obtained with four lamps on and it was equal to $57.6 \mathrm{mg}$ of ozone per minute.

Table 1. Operating parameters

\begin{tabular}{cc}
\hline Parameter & Value \\
\hline Flow rate & $13 \mathrm{lpm}$ \\
\hline Volume of reactor & $0.0776 \mathrm{~m}^{3}$ \\
\hline Overall Length of each lamp & $287 \mathrm{~mm}$ \\
\hline Lamp Wattage & $14 \mathrm{~W}$ \\
\hline
\end{tabular}

Table 2. UV lamps parameter

\begin{tabular}{cc}
\hline Parameter & Value \\
\hline Overall Lenght (OL) & $287 \mathrm{~mm}$ \\
\hline Bulb Diameter (BD) & $15 \mathrm{~mm}$ \\
\hline Radiating Lenght (RL) & $212 \mathrm{~mm}$ \\
\hline Base Material & ceramic \\
\hline Wattage & $14 \mathrm{~W}$ \\
\hline Current & $425 \mathrm{~mA}$ \\
\hline Voltage & $34 \mathrm{~V}$
\end{tabular}

Table 3. Ozone production rate

\begin{tabular}{ccc}
\hline $\begin{array}{c}\text { Number of lamps } \\
\text { on }\end{array}$ & Voltage [V] & $\begin{array}{c}\text { Ozone rate } \\
\text { [mg/min] }\end{array}$ \\
\hline 1 & 34 & 45.6 \\
\hline 2 & 68 & 52.8 \\
\hline 4 & 136 & 57.6 \\
\hline
\end{tabular}




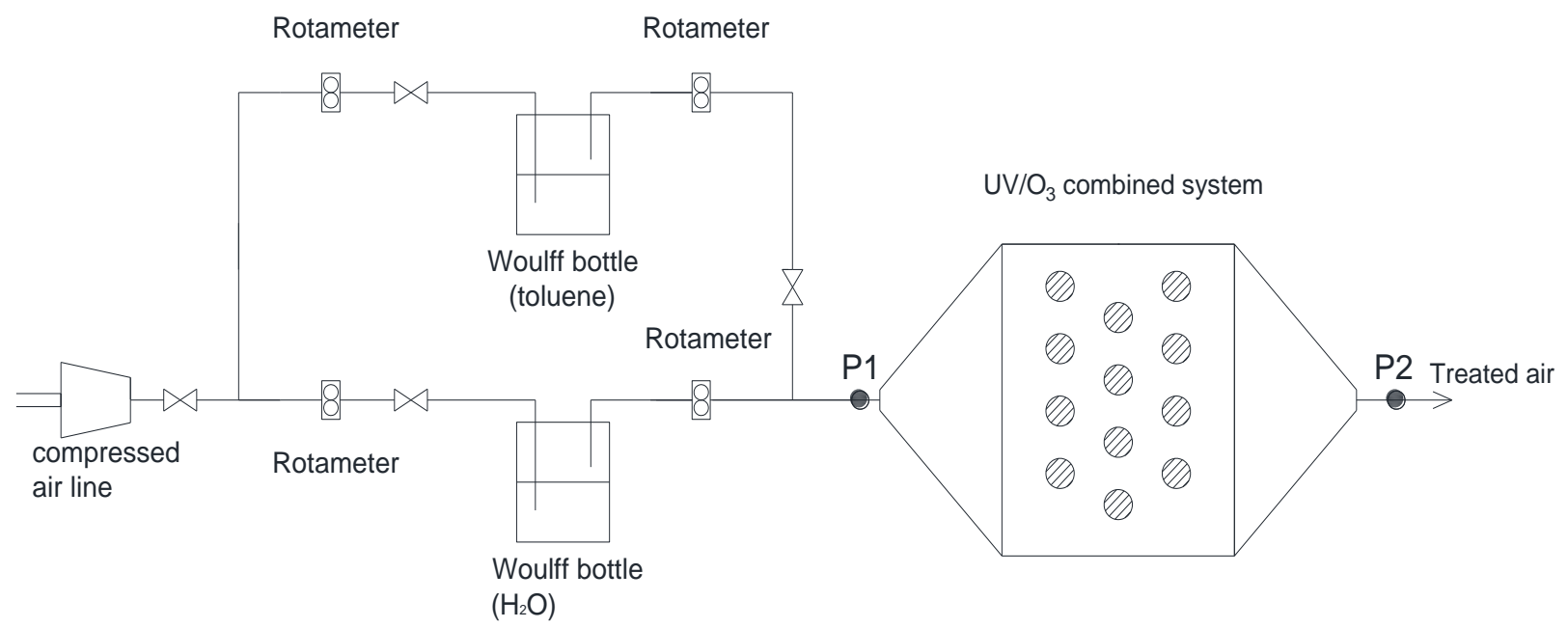

Figure 1. Experimental set-up system

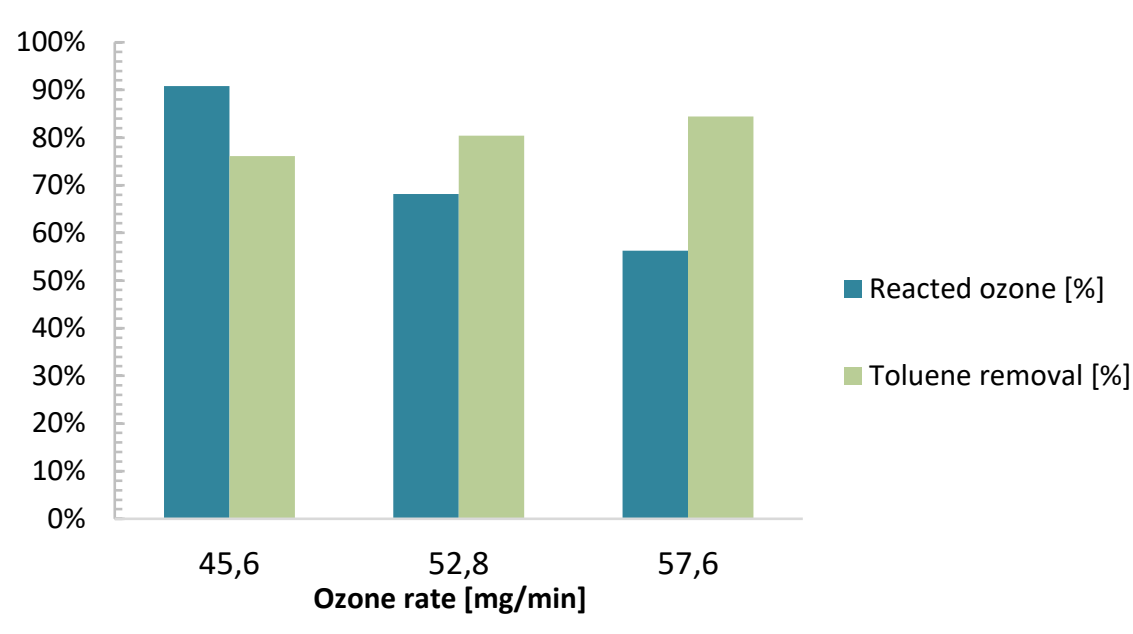

Figure 2. Toluene removal efficiencies and reacted ozone as a function of the ozone rate

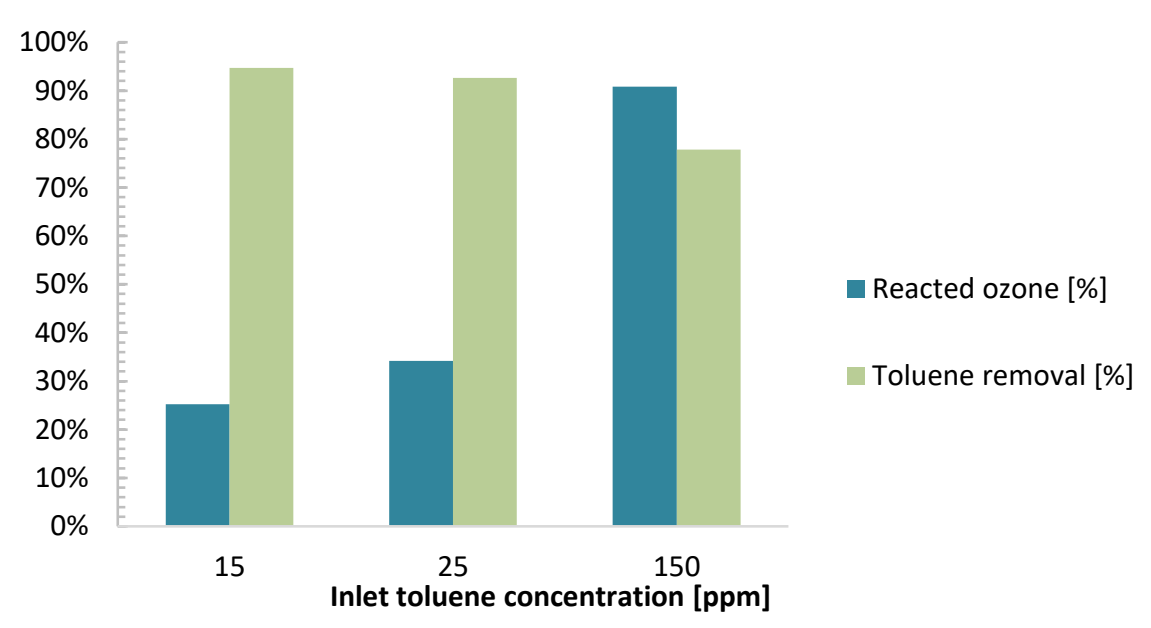

Figure 3. Toluene removal efficiencies and reacted ozone as a function of the inlet toluene concentration

\section{Results and discussion}

In Figure 2 are reported the results in terms of toluene removal and reacted ozone percentages as function of the ozone dose. Increasing the applied voltage from 34 to $136 \mathrm{~V}$, which resulted corresponding to an increasing of ozone rate from $45.6 \mathrm{mg} / \mathrm{min}$ to $57.6 \mathrm{mg} / \mathrm{min}$, the removed toluene moved from the $76 \%$ to the $84 \%$. In the same time, the reacted ozone decreased from $91 \%$ to the $56 \%$. Toluene removals up to $84 \%$ were obtained with regards to the contaminated stream at concentrations between 150 and $170 \mathrm{ppm}$, corresponding to an incoming load of 7,34- 
$8,32 \mathrm{mg}$ of toluene per minute. For the range of toluene concentration between 150 and $170 \mathrm{ppm}$, in the investigated operating conditions, the ozone did not constitute a limiting factor. For this reason, the efficiencies in terms of toluene removal resulted quite similar variating the applied power. In Figure 3 are reported the results as a function of the incoming toluene concentration, for an applied voltage of $34 \mathrm{~V}$ (" $\mathrm{A}$ " lamp on). The results showed, even for an incoming concentration of $150 \mathrm{ppm}$, a removal of $78 \%$ of toluene, obtained turning on only the " $A$ " lamp. The flow rate and, consequently, the residence time were maintained constant for the whole set of experiments. The preliminary results obtained in the above-mentioned operating conditions highlighted the removal of the odours for the investigated streams.

\section{Conclusions}

The preliminary results of the present work highlighted as the investigated process may be suitable with the aim at treating waste gas from environmental and industrial facilities in which are involved processes of organic degradation. In the investigating conditions, referring to inlet toluene concentrations in the range between 10-20 ppm of toluene, the results showed as the reactor may be considered over dimensioned; the ozone in the outlet stream, indeed, resulted over the $60 \%$ of the ozone produced. For incoming concentration equal to $150 \mathrm{ppm}$, also with the lowest ozone dose, a significant removal of toluene was obtained. The combination with an additional treatment may be implemented, with a view at reducing the emissions of oxidants and maximizing the removal of organic compounds.

\section{References}

Alfonsín C., Lebrero R., Estrada J.M., Muñoz R., Kraakman N.J.R. (Bart), Feijoo G. and Moreira M.T. (2015), Selection of odour removal technologies in wastewater treatment plants: A guideline based on Life Cycle Assessment, The Journal of Environmental Management, 149, 77-84, doi:10.1016/j.jenvman.2014.10.011.

Belgiorno V., Naddeo V. and Zarra T. (2012), Odour Impact Assessment Handbook, John Wiley \& Sons, Inc., 288 p., ISBN: 978111996928-0.

Bindra N., Dubey B. and Dutta A. (2015), Technological and life cycle assessment of organics processing odour control technologies, The Science of the Total Environment, 527-528, 401-412, doi:10.1016/j.scitotenv.2015.05.023.

Chou M.-S., Huang B.-J. and Chang H.-Y. (2005), Decomposition of Gas Phase 1,3-Butadiene by Ultraviolet/Ozone Process, The Journal of the Air \& Waste Management Association, 55, 919929, doi:10.1080/10473289.2005.10464679.

Estrada J.M., Kraakman N.J.R., Lebrero R. and Muñoz R. (2015), Integral approaches to wastewater treatment plant upgrading for odor prevention: Activated sludge and oxidized ammonium recycling, Bioresource Technology, 196, 685-693, doi:10.1016/j.biortech.2015.08.044.

Giuliani S., Zarra T., Nicolas J., Naddeo V., Belgiorno V. and Romain A.-C. (2012), An alternative approach of the e-nose training phase in odour impact assessment, Chemical Engineering Transactions, 30, 139-144.
Hołub M. (2014), Plasma Supported Odour Removal from Waste Air in Water Treatment Plants: An Industrial Case Study, Aerosol and Air Quality Research, doi:10.4209/aaqr.2013.05.0171.

Idi A., Md Nor M.H., Abdul Wahab M.F. and Ibrahim Z. (2015), Photosynthetic bacteria: an eco-friendly and cheap tool for bioremediation, Reviews in Environmental Science and Biotechnology, 14, 271-285, doi:10.1007/s11157-014-9355-1.

Iranpour R., Cox H.H.J., Deshusses M.A. and Schroeder E.D. (2005), Literature review of air pollution control biofilters and biotrickling filters for odor and volatile organic compound removal, Environmental Progress, 24, 254-267, doi:10.1002/ep.10077.

Lebrero R., Rodríguez E., García-Encina P.A. and Muñoz R. (2011), A comparative assessment of biofiltration and activated sludge diffusion for odour abatement, Journal of Hazardous Materials, 190, 622-630, doi:10.1016/j.jhazmat.2011.03.090.

Lucernoni F., Tapparo F., Capelli L. and Sironi S. (2016), Evaluation of an Odour Emission Factor (OEF) to estimate odour emissions from landfill surfaces, Atmospheric Environment, 144, 87-99, doi:10.1016/j.atmosenv.2016.08.064.

Mudliar S., Giri B., Padoley K., Satpute D., Dixit R., Bhatt P., Pandey R., Juwarkar A. and Vaidya A. (2010), Bioreactors for treatment of VOCs and odours - A review, The Journal of Environmental Management, 91, 1039-1054, doi:10.1016/j.jenvman.2010.01.006.

Naddeo V., Belgiorno V. and Zarra T. (Eds.) (2013), Odour Impact Assessment Handbook, Wiley, A John Wiley \& Sons, Ltd., Publications, Chichester, West Sussex, United Kingdom.

Naddeoa V., Zarraa T., Olivaa G., Chiavolab A. and Vivarellic A. (2016a), Environmental odour impact assessment of landfill expansion scenarios: Case study of Borgo Montello (Italy), Chemical Engineering, 54.

Naddeoa V., Zarraa T., Olivaa G., Kubob A., Ukidab N. and Higuchib T. (2016b), Odour measurement in wastewater treatment plant by a new prototype of e. nose: Correlation and comparison study with reference to both European and Japanese approaches, Chemical Engineering, 54.

Navia R. and Muñoz R. (2015), Biotechnologies for Gaseous Emissions and By-products Management in Waste Treatment Facilities, SAGE Publications.

Paz Y. (2010), Application of TiO2 photocatalysis for air treatment: Patents' overview, Applied Catalysis B: Environmental, 99, 448-460, doi:10.1016/j.apcatb.2010.05.011.

Swetha G., Gopi T., Chandra Shekar S., Ramakrishna C., Saini B. and Rao P.V.L. (2017), Combination of adsorption followed by ozone oxidation with pressure swing adsorption technology for the removal of VOCs from contaminated air streams, Chemical Engineering Research and Design, 117, 725-732, doi:10.1016/j.cherd.2016.11.036.

Viccione G., Zarrab T., Giulianib S., Naddeob V. and Belgiornob V. (2012), Performance study of e-nose measurement chamber for environmental odour monitoring. Chemical Engineering, 30.

Wang Z., Xiu G., Qiao T., Zhao K. and Zhang D. (2013), Coupling ozone and hollow fibers membrane bioreactor for enhanced treatment of gaseous xylene mixture, Bioresource Technology, 130, 52-58, doi:10.1016/j.biortech.2012.11.106.

Yao H. and Feilberg A. (2015), Characterisation of photocatalytic degradation of odorous compounds associated with livestock 
facilities by means of PTR-MS, Chemical Engineering Journal, 277, 341-351, doi:10.1016/j.cej.2015.04.094.

Zarra T., Naddeo V., Belgiorno V., Reiser M. and Kranert M. (2009), Instrumental characterization of odour: a combination of olfactory and analytical methods, Water Science and Technology: A Journal of the International Association on Water Pollution Research, 59, 1603-1609, doi:10.2166/wst.2009.125.

Zarra T., Giuliani S., Naddeo V. and Belgiorno V. (2012), Control of odour emission in wastewater treatments plants by direct and undirected measurement of odour emission capacity, Water Science and Tecnhnology, 66(8), 1627-1633.

Zarra T., Reiser M., Naddeo V., Belgiorno V. and Kranert V. (2012b), A comparative and critical evaluation of different sampling materials in the measurement of odour concentration by dynamic olfactometry, Chemical Engineering Transactions, vol. 30, p. 307-312, ISSN: 1974-979. 